\title{
IT Professional role today and tomorrow
}

\author{
Colin Thompson
}

(BCS, UK)

\begin{abstract}
As IT professionals we live in exciting times. The IT profession is coming of age and the role of the IT professional is changing rapidly. The traditional IT Department, as a support function dedicated to providing technical solutions to problems defined by 'the busness', is set to disappear. The reality today is that IT doesn't just support business, it powers business and the future for the IT profession is all about the development of business-focussed professionals with a much wider range of skills and capabilities than in the past.

Information technology can, and in many instances does, deliver very substantial business and social benefits. It enables organisations to make dramatic leaps in productivity and governments to deliver greatly enhanced service levels that their citizens now expect. But successful IT enabled business change often remains elusive. If we are to realise the full potential of IT the function must move from being viewed as a technical solution provider to be seen as a full transformation partner.

This article draws on UK experience over the past 5 years to outline what all this will mean for IT professionals, for the IT profession and for the institutions that support the profession.
\end{abstract}

\section{Background}

Few things are more critical to the well-being, wealth and welfare of the citizens of the 21st century than the quality of our information and communication systems. Healthcare, the security of savings, the ability of our companies to compete and the overall health of our national economies; every facet of our personal and business lives, from the mundane to the life-critical, is heavily dependent on computer-based systems and, in consequence, on the competence and professionalism of those who design, build, implement and manage those systems.

Over the past few years there has been rapidly growing recognition of the need to improve consistency in the way new IT systems are developed and complex ITenabled change programmes are managed. That recognition is driven not just by the need to reduce the risk and cost of failure but increasingly by the need to maximize the dividends of successful IT enabled innovation. Business managers are now acutely aware that exploiting the full potential of IT is fundamental to their ability to compete and to meet customer expectations. Governments too have recognised that effective IT systems are critical to their ability to deliver improved 
service to their citizens and, in the UK, the drive towards a more professional approach has been led to some extent by the pressure government has exerted on IT service suppliers.

It was against this background, in early 2005, that the British Computer Society set up a major programme designed to improve both capability and performance in the effective exploitation of IT. The programme has had the active support of other professional institutions and trade bodies and of leading members of the IT and business communities drawn from both the public and private sectors. Significantly, the key objectives ${ }^{1}$ for the programme are aimed not at improving the traditional technical performance of IT practitioners but on improving the ability of organisations to exploit the full benefits that IT has to offer:

- To improve the ability of business and other organisations to exploit the potential of information technology effectively and consistently by increasing professionalism

- To build an IT profession that is respected and valued by its stakeholders government, business leaders, IT employers, IT users and customers - for the contribution that it makes to a more professional approach to the exploitation and application of IT

These objectives reflect the recognition that a fundamentally new vision is required if the IT profession is to command fully the respect and commitment of its various stakeholders and to play its full part in improving capability and performance. The existing vision, built round a narrow image of activity focussed essentially on technical and engineering issues, will not provide a base for securing the necessary commitment or for driving the required changes. The need now is for an IT profession that has a much greater business focus and which has appropriate business and other non-technical competences to play a full part in all stages of IT exploitation. It must also be a profession that demands much greater personal responsibility and accountability of its practitioners and which requires regular re-accreditation to ensure that its qualifications provide evidence of current, rather than historic, competence. Crucially, it must also be a profession which covers both the 'I' and the ' $T$ ' of IT - it must be as much about Information as about Technology.

The need for a more business-focussed IT profession to meet the changing needs and expectations of customers was underlined by a global survey of senior IT and business leaders undertaken by the Economist Intelligence Unit in $2006 .{ }^{2}$ $69 \%$ of those surveyed - and $83 \%$ of the CEOs and Board members surveyed were convinced that the primary role of IT must shift rapidly from driving cost efficiency to enabling revenue growth.

1 The Professional (C) 2008 The British Computer Society

2 Great Expectations: The changing role of IT in business. Economist Intelligence Unit September 2006. 


\section{ASSESSMENT NOW (2006)}

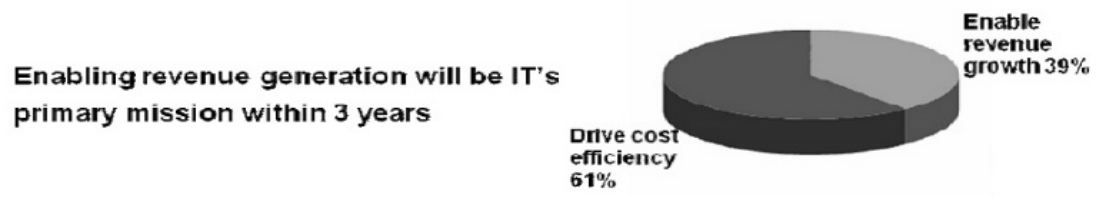

$83 \%$ of CEOs and board members are convinced of it.

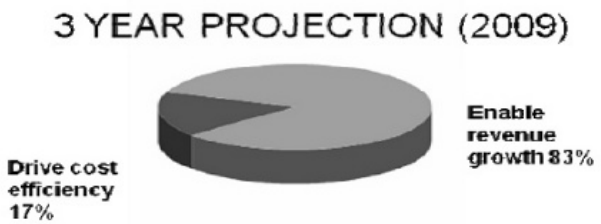

Whether things will have moved this dramatically by 2009 is doubtful but the survey is significant more for the underlying shift in attitude which it reflects than for the quality of its prediction.

This shift in focus represents a considerable challenge for the IT profession and for IT professionals, not least in terms of the new competences and capabilities that will be required. Few would claim that the profession is currently equipped for the new role but it must clearly become so if it is to support both business and wider society in securing the full benefit from IT.

The importance of the traditional technical skills and competences should not be underestimated or undervalued but, as we move further into the $21^{\text {st }}$ century, it will be the ability to exploit both the information and the technology to deliver business and public benefit rather than technical excellence in itself that will distinguish the most successful businesses and national economies. In short, the IT profession has to move from its traditional role of technical solution provider to become a full transformation partner with the business organisations that it serves.

\section{The IT profession}

The UK Professionalism programme has included extensive research led by BCS and supported by major organisations in the industry. One of the main aims of that research has been to define the essential characteristics of the IT profession of the future. What, for example, will be the scope of the new profession in terms of practitioner competences, and how do we build a mature profession that will stand comparison with the older professions such as law, medicine and accountancy?

The ambition is to shape and create a mature IT profession with clearly defined professional standards. This will involve putting in place the necessary 
infrastructure and ensuring that the principles of professionalism are firmly embedded in standard practice. Some idea of the complexity can be gained from the diagram below.

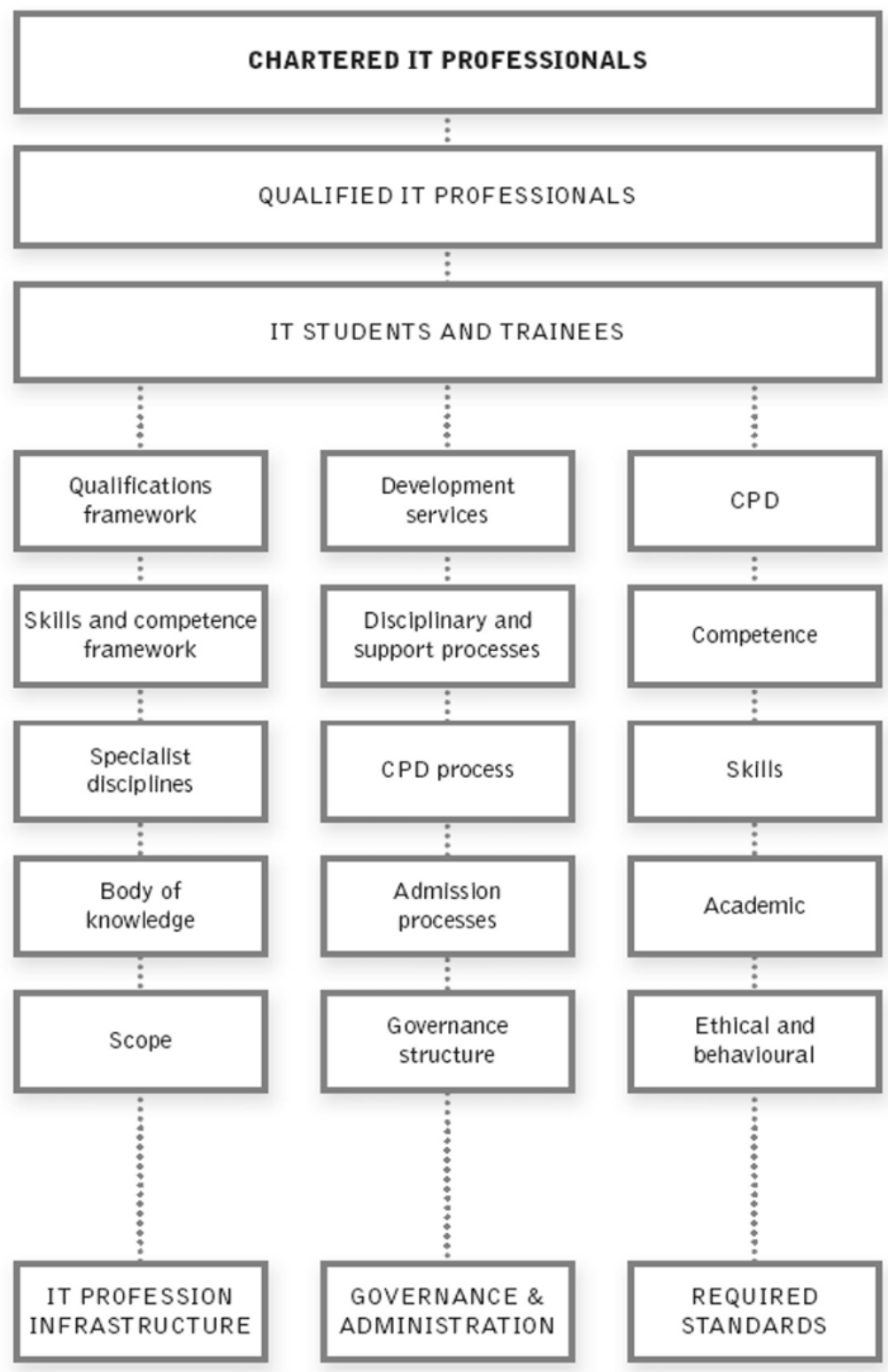

Figure 2: Building the fully effective IT profession (C) 2008 The British Computer Society 
Professional institutions must take the lead here by defining standards, making the governance and administration arrangements and contributing to the professional infrastructure through products and services.

\section{Scope of the Profession}

With the spread of the use of IT into every part of our lives the roles undertaken by IT practioners have expanded. There are groups of practitioners who now operate in areas focussed on business change and transformation which can feel far removed from the traditional technological base of the IT profession. These practitioners cannot rely solely on their technical skills but also require skills more atuned to business leadership and management.

There is growing evidence of fluid boundaries between the competence sets of IT professionals and the competence sets of those in other professions such as finance, personnel, training and procurement. The scope of the IT profession is expanding and can be illustrated as follows:

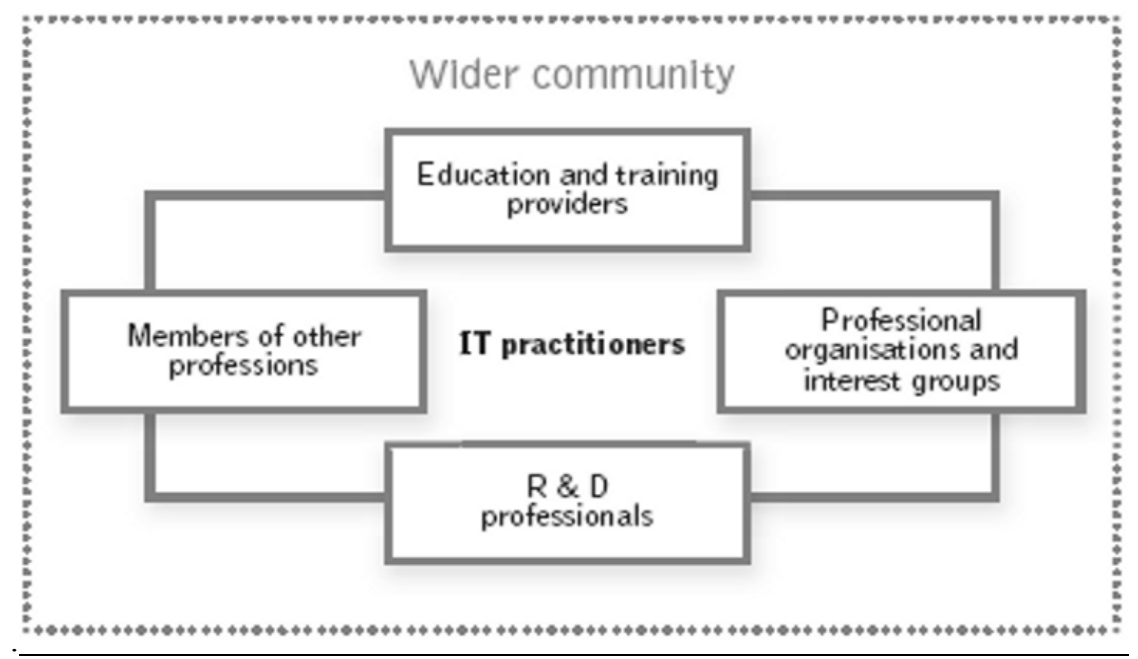

Figure 3: Scope of the profession (C) 2008 The British Computer Society

The work on practitioner scope within the UK has been led by the IT Sector Skills Council, e-skills $\mathrm{UK}^{3}$ and has involved extensive consultation with the IT employer community. The result of that work is summarised in the following diagram which provides the basis for the essential segmentation of the new profession into recognised disciplines and specialisms:

3 www.e-skills.com 


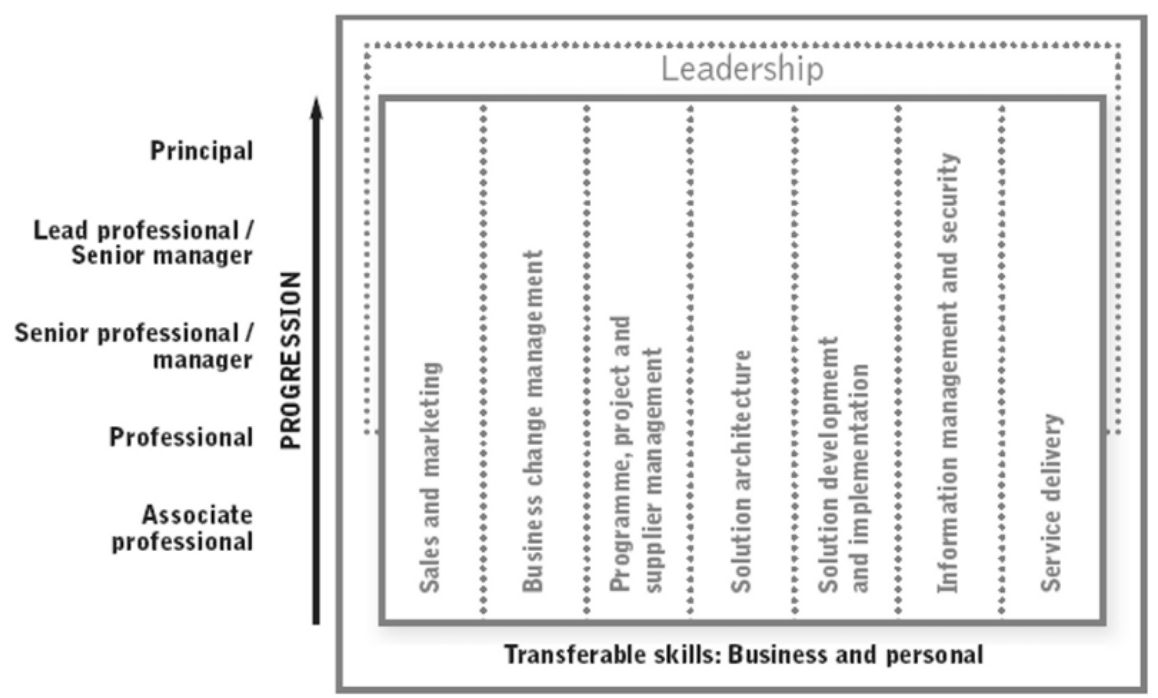

Figure 4: Professional Competency Model (C) e-skills UK Sector Skills Council ltd 2000-2007

Complementing this model the SFIA ${ }^{4}$ (Skills for the Information Age) framework provides a common reference model for the identification of the skills needed to develop effective Information Systems (IS) making use of Information \& Communications Technology (ICT) and enables employers of IT professionals to carry out a range of HR activities against a common framework of reference.

SFIAplus ${ }^{\mathrm{TM}}$ created by BCS to provide a more comprehensive tool, enables benchmarking of both individuals and jobs, whilst providing detailed pointers to training and development resources. This model also underpins an extensive range of BCS professional development products supporting both practitioners and organisations.

\section{Competencies for senior roles}

Further research carried out under the BCS Professionalism programme looked at the competencies and capabilities of the most successful Chief Information Officers (CIOs), and others in senior positions. The results ${ }^{5}$ suggest that whilst foundation technical and managerial competencies are still important these are not the competencies that drive distinctive performance by those in senior positions. Those foundation competencies will typically be developed and applied by

${ }^{4}$ Skills for the Information Age: www.sfia.org.uk

${ }^{5}$ A Competency Framework for Chief Information Officers and Senior Leadership Positions (C) 2008 The British Computer Society 
individuals as they progress through their careers but the defining competencies when they reach senior positions are likely to be those associated with leadership rather than any technical capability.

\section{Building a mature IT profession}

Establishing a mature professional infrastructure will be critical if IT professionals are to be supported through the required changes in roles and responsibilities. Clearly, if the ambition is to reach maturity, we need to understand just where we are on that journey at the present time and just what full maturity will look like when we get there. This aspect of the BCS research involved consultation with a wide range of established professional institutions covering other disciplines such as accountancy and medicine and more modern ones such as human resources and purchasing. The following diagrammatic representation provides an indication of the task facing us as we move the profession towards maturity.

The current level of maturity of the IT profession is estimated at between level 1 and 2; to meet the ambition for parity with other established professions we have to rise to at least level $4 .^{6}$

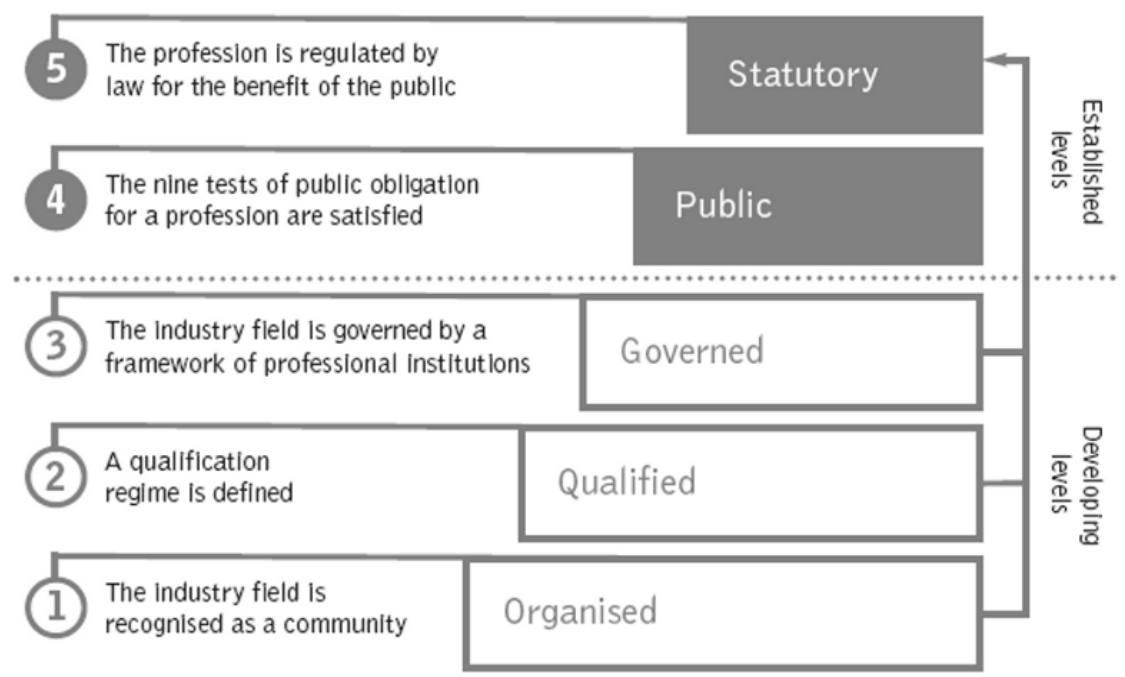

Figure 5: Profession maturity model derived from the Carnegie Mellon University Capability Maturity Model ${ }^{\circledR} \quad$ C 2008 The British Computer Society

${ }^{6}$ Establishing IT as a Profession (C) 2008 The British Computer Society 


\section{Benefits and Opportunities}

One of the early lessons from the UK Professionalism Programme was that nobody ever votes against professionalism; no one ever argues that it is not a good thing. But it is also very clear that few are prepared to make a positive commitment to implement the principles of professionalism until they can see some clear business benefit sufficient to justify the investment required. It is also apparent that many people do not recognise the full scope and ramifications of professionalism, often mistakenly equating it solely with the attainment of a technical qualification or a relevant degree.

In the longer run we believe that the case for professionalisation will be self evident. The business world in which the IT profession operates is changing rapidly and those who do not recognise the need for change, or do not respond to that need, are likely to be left behind. In the meantime the business case for a more mature IT profession, working within a professionalised IT industry and business environment is strong and evidenced by the following quotes:

"Annual cost of IT failure in Europe is \$140.5 billion" - Gartner

"Effectively managed people assets have the potential to increase shareholder value by 30\%." - Aberdeen Group

"Competent suppliers working with competent customers are 8 times more likely to deliver successful projects" - UK Office of Government Commerce A report from the Royal Academy of Engineering and the $\mathrm{BCS}^{7}$ noted "There is an exceptionally large discrepancy between best practice and common practice in IT".

Benefits for all stakeholders could be substantial, including significant improvements in:

- Project and programme success

- IT enabled business transformation capability

- Governance and compliance

- Business returns from IT investment

- Competitive edge for both IT suppliers and their customers

- Service delivery for both public and commercial organisations

- IT staff recruitment and retention

- Exploitation of information assets

- Career challenge and development for IT professionals

Customers for the services of the IT industry can expect improved project success rates with stronger innovation capability carried out by more effective and motivated staff.

7 The Challenges of Complex IT Projects (C) The Royal Academy of Engineering. 
Suppliers of IT services will benefit from a competitive edge in bidding for new business, improved consistency of development and delivery and improved relationships with customers. These benefits will in turn lead to enhanced business reputation.

For the IT practitioner there is an ambition that a mature IT profession with clearly defined professional standards will attract high quality people, inspire high performance and represent a career aspiration and opportunity for a wide spectrum of people. These practitioners will benefit from higher rewards, improved career opportunities, more varied job opportunities and increased recognition and respect.

\section{What makes a Practitioner Professional?}

So what is it that distinguishes 'a professional'? And just what does 'professionalism' really mean? These were two of the question which the BCS programme needed to answer at an early stage. In response to the first question it produced the following definition.

A fully established professional is a practitioner who has specific skills rooted in a broad base and appropriate qualifications, belongs to a regulated body, undergoes continuous development, operates to a code of conduct and recognises personal accountability. ${ }^{8}$

This definition is illustrated by the following diagram

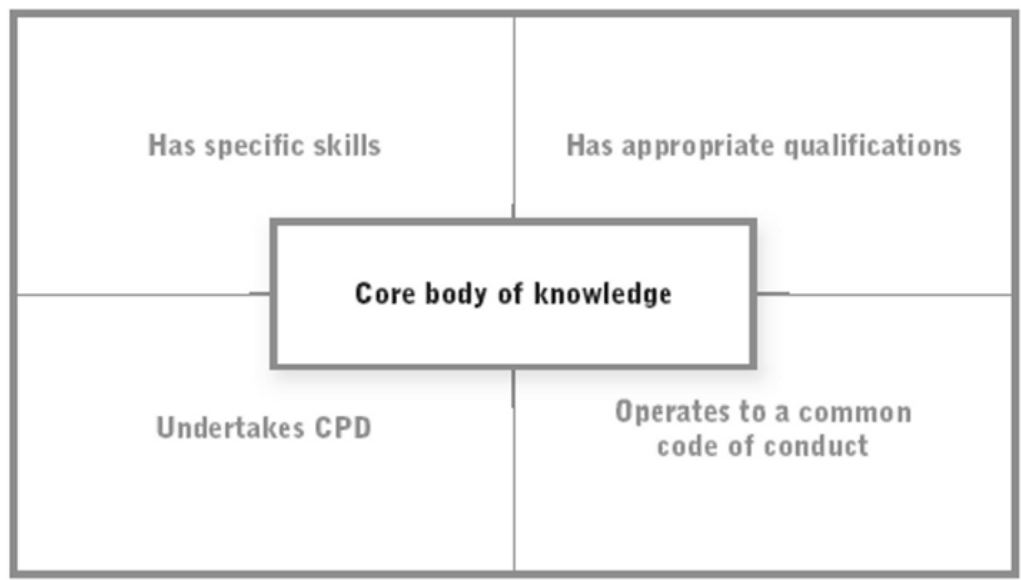

Figure 6: A Professional Practitioner (C) 2008 The British Computer Society

The essential elements of professionalism are three-fold - competence, integrity and public obligation. Competence is the demonstration of relevant, up-

8 The Professional C 2008 The British Computer Society 
to-date skills and capabilities appropriate to the particular task or role with practical experience to complement theoretical knowledge. These capabilities must be combined with a range of non-technical competences including communication and inter-personal skills, domain or business knowledge and, for many, the ability to lead or manage. These competences need to be underpinned by a broader foundation of experience, knowledge and understanding, backed by relevant qualifications and maintained by continuing professional development.

The second element encompasses Integrity, Responsibility and Accountability. A commitment to a published code of conduct, including ethical standards, which ideally is recognised and administered by the professional community, is essential. In parallel with the ethical considerations, and equally vital, is recognition that professionals have a set of obligations and responsibilities to the profession which sit alongside those to their employer or contract of employment. There is a matching professional accountability - justification for their actions and decisions lies firmly with the individual professional. Excuses such as "I was only following instructions" or "I did what the contract stated" are unacceptable to justify a course of action and in many countries are not acceptable in a court of law.

The final element of professionalism is the recognition that professionals have a public obligation. A professional is required to work in the best interest of society and to use their knowledge, skills, attributes and experience to apply IT diligently and carefully for the public good. This requirement, combined with that of personal accountability, places an onerous responsibility on the practitioner not only to make balanced and thoughtful decisions but to understand and be willing to explain the ramifications and consequences of those decisions and the impacts they will have on others.

Justice Sandra Day O'Connor, recently retired from the US Supreme Court summed up the essence of professionalism as:

“A commitment to develop one's skills to the fullest and apply them responsibly to the problems at hand. Professionalism requires adherence to the highest ethical standards of conduct and a willingness to subordinate narrow self-interest in pursuit of the more fundamental goal of public service".

The progressive attainment of professional ethos necessitates a hierarchy of standards and qualifications to acknowledge progress and achievement and to set public expectations. Such systems have been, and are continuing to be, developed in Australia, Canada, UK, the USA and elsewhere. In the UK the BCS has introduced Chartered IT Professional (CITP) as the gold standard to recognise professional IT practitioners. There are more than 17,000 registered CITPs and the number is growing rapidly as individuals and employers recognise the importance of defining and acknowledging the achievement of professionalism. 


\section{What Defines an IT-capable organisation?}

While the creation of a mature, business-focussed IT profession is an essential element of the capability to exploit IT fully, it is not sufficient in itself. IT professionals can only be fully effective in organisations which have a wider professional culture and which are led by IT-competent business managers. Given this wider dependency it is important that the IT profession should take a proactive approach not just to improving its own professionalism but also to improving the business environment in which it operates. In the UK the BCS has done exactly that, working with other leading professionals, government, IT employers, institutions and trade associations to improve professionalism across a broad front.

In the area of business leadership, BCS has partnered with the Chartered Management Institute looking at the contribution of the Chief Executive in driving successful major change programmes. The report ${ }^{9}$ from this project identified five key challenges facing senior executives in structuring, leading and implementing large and complex IT-driven business change.

- Creating transformational value rather than just implementing IT projects

- Building capability for ongoing change. Being able to predict future business needs and how IT can help shape new business models and deliver the desired benefits

- Creating a climate of open communication

- Managing confidence and risk - understanding the impact of external changes

- Building personal capability, learning and confidence.

The report concluded that CEOs need to have a growing understanding of the strategic use of IT to ensure that their organisations are ready to capitalise on the new opportunities it provides. Specifically, they need to have external environmental developments on their radar so that they can actively manage the implications for internal IT change programmes and in particular, active and visible leadership is required to avoid the twin traps of:

- extended implementation timeframes

- lack of full exploitation of business benefits.

\section{A Professional Future}

The work undertaken so far in the UK, has highlighted the enormous opportunity that now exists to create an IT profession driving a vastly improved

9 Business Leadership of Technological Change : Five Key Challenges Facing CEOs (C) 2008 The British Computer Society 
capability to exploit fully the potential of IT. The more recent work by the IFIP International Professional Practice Programme Task Force has demonstrated that this is a global opportunity - indeed the extent of globalization of the IT industry itself now makes it essential that we address this issue on an international basis.

The IT profession stands at a critical point in its development; responding to this opportunity will require a very different kind of IT profession and a body of IT professionals with a much wider range of knowledge and competence. Technical competence will remain important but there will be an increasing demand for IT practitioners with business, management and leadership skills.

This new IT profession must be focussed on business outcomes and play a full part at all stages of IT enabled business change programmes and projects. If the full potential of information and technology is to be realised, the IT function must move from being viewed as a support cost to being seen as an essential contributor to revenue generation, service improvement and business transformation.

Adapting to meet the challenge will not be easy for either the profession or the professionals. The changes for both are significant but so too are the potential benefits for all stakeholder communities. For the IT practitioner in particular the changes will mean higher rewards, improved career opportunities, increased recognition and the opportunity to play at a much more strategic level within organizations. And the IT profession which emerges from this process should be one which will stand alongside the accountancy profession in terms of influence and importance in the business world.

Turning this vision into reality will take both time and effort. As illustrated by the maturity model shown earlier in this article, we are still some way behind many of the older, more traditional areas of professional activity. But, unlike those other professions, we have the chance to put in place, almost from the outset, a coherent international professional structure to meet the needs of a global industry. That is a unique opportunity which we must now grasp and exploit. 